\title{
No Human Vehicle Tolling System
}

\author{
Kanishk Chhabra ${ }^{1}$ \\ ${ }^{1}$ St. Mark’s Sr. Sec. Public School, India.
}

\begin{abstract}
ARTICLE INFO
Keywords:

safety; accidents;

live-saving

ABSTRACT

The prototype aims to minimize the number of Accidents occurring on roads due to Red-light Jumping, over speeding and Drunk and Drive cases. In addition, it would address the issues such as Emergency Lanes Misuse, Deaths in Ambulance due to traffic related delays.

Road accidents is the 8th leading cause of human death per annum. Day to day observations indicate, Indians in particular follow traffic rules not because of safety but out of fear of being penalized. E.g. people avoid red light jumping if they see a cop stationed right next to traffic signal.

"NO HUMAN VEHICLE TOLL SYSTEM" prototype utilizes Radio Frequency Identification (RFID) Technology and camera projections. It detects the RFID tags via radio waves pre-installed in vehicles. RFID readers installed on the roads would read RFID tags using radio waves, the moment a vehicle passes through it. The signal would then be send to the microcontroller for further processing. Arduino Mega microcontroller is utilized in the prototype. The microcontroller connected to internet commands the server to search for unique RFID tag in the database and advances the process per protocol. To make the system more robust, AI cameras are being utilized to take pictures of the registration plates for reconfirmation before ticket issuance.

Based on the above, the prototype would potentially address issues such

- Traffic Signal Jumping, Over speeding, Intentional hindrance of Emergency Vehicles, tracking lost vehicle(s), Fake Registration Plate Detection, Driving without Seatbelt and Helmet, Drinking and Driving In terms of numbers, it may result in $80 \%$ reduction in road accidents.
\end{abstract}

\section{Introduction}

\subsection{Purpose of The Prototype}

To minimize the number of road-accidents due to Traffic-Signal Jumping, Over Speeding and Drinking \& Driving. In addition, it would address issues such as Misuse of Emergency Lanes, patient's death in Ambulance due to traffic delays.

\footnotetext{
$\square$ Corresponding Author E-Mail Address: kanishkchhabra23@gmail.com
} 


\subsection{Statistics}

Per published report in 2016, road accidents is the 8th leading cause of human death per annum. People jump traffic signals to save few minutes. In majority cases, it leads to accidents causing severe injuries as wells as deaths. In 2018, 4.76 Million people died due to road accidents which is the maximum till date. In 2018, over 977 Thousand people died due to Road injuries. (Source: Our World in Data)

Figure 1: Top 10 global causes of Deaths 2016

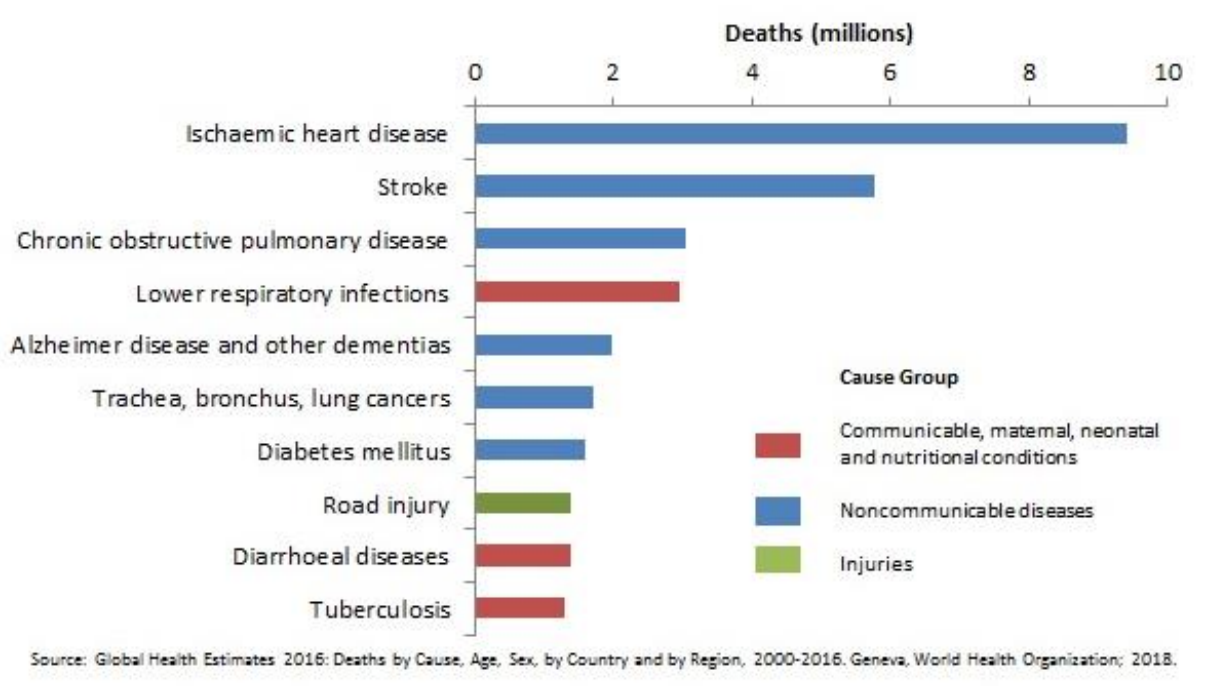

Source: World Health Organisation (WHO)

\section{Body of The Paper}

"No Human Vehicle Toll System" is a prototype which utilizes RFID Technology. It detects the RFID tags via radio waves pre-installed in vehicles. RFID readers installed on the roads would detect RFID tags using radio waves, the moment vehicle passes through it. The reader would read the tag and send the signal to microcontroller for further processing.

\subsection{Is This Prototype Energy Efficient?}

Yes, it works on $12 \mathrm{~V}$ and $1 \mathrm{~A}$ current.

Per formulae, Electrical Energy $=$ Voltage $\mathrm{x}$ Current $\mathrm{x}$ Time

E.E. $=\mathrm{V} \times \mathrm{I} \times \mathrm{T}$

Now, substituting the values,

E.E. $=12 \times 1 \times 1$ $=12$ Watt hour

What is the conversion of Watthour to Units per month? 
Now converting it into units, it consumes 8.64 Units per month which is almost ₹34.56 or $\$ 0.50$.

\subsection{Existing Solution to Problems in India?}

There is an Existing solution - it is named as "E- Fine". In this system, a policeman sends the offender's information to the user's portal where the offender is supposed to pay the fine online. However, it suffers from numerous limitations. E.g.

1. Policemen have to keep an eye on the road $24 \times 7$ through security cameras, which may lead to multiple errors.

2. If a car jumps the red light, sometimes the policemen may not be able to capture the right image making it questionable.

Due to multiple limitations, the above system was discontinued from Mumbai in 2017.

\subsection{Comparison of RFID Tags}

Six different RFID tags were tested to be used in vehicles.

Table 1: Comparison of 6 different RFID tags at different speed and from Different distance

\begin{tabular}{|c|c|c|c|c|}
\hline RFID TAGS & $\begin{array}{c}\text { At 25 } \\
\text { Miles/Hour } \\
\text { From 10 Feet }\end{array}$ & $\begin{array}{c}\text { At 25 } \\
\text { Miles/Hour } \\
\text { From 18 Feet }\end{array}$ & $\begin{array}{c}\text { At 45 } \\
\text { Miles/Hour } \\
\text { From 10 Feet }\end{array}$ & $\begin{array}{c}\text { At 45 } \\
\text { Miles/Hour } \\
\text { From 18 Feet }\end{array}$ \\
\hline $\begin{array}{c}\text { NOX-TM 15 } \\
\text { Long range } \\
\text { durable metal } \\
\text { or non-metal } \\
\text { mount tag }\end{array}$ & & & & \\
\hline $\begin{array}{c}\text { NOX-TM 9 } \\
\text { Min range } \\
\text { durable metal } \\
\text { mount tag }\end{array}$ & & & & \\
$\begin{array}{c}\text { NOX 2 } \\
\text { AD 223 and } \\
\text { UMP long } \\
\text { range RFID } \\
\text { tags mounted } \\
\text { on plastic }\end{array}$ & & & & \\
\hline $\begin{array}{c}\text { UMP } \\
\text { Long range } \\
\text { windshield } \\
\text { mounted RFID } \\
\text { tags }\end{array}$ & & & & \\
\hline $\begin{array}{c}\text { AD 223 } \\
\text { Long range } \\
\text { windshield }\end{array}$ & & & & \\
\hline
\end{tabular}




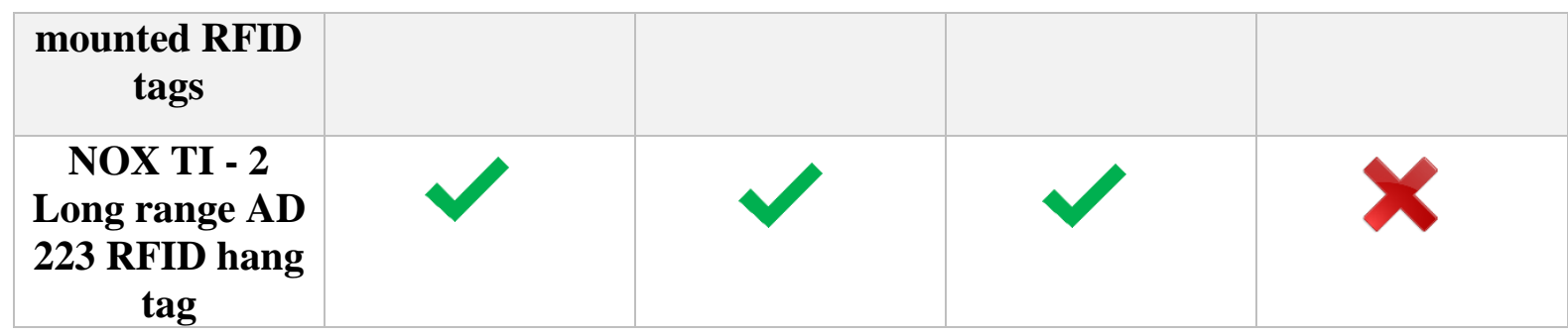

Source: Tried by own and Simply RFID

*AD 223 only works when car is stationary.

Majority silicon chips fail to operate at temperatures >125 degrees Celsius (257 degrees Fahrenheit)

Per above Table, NOX-TM 15 and NOX-TM 9 are the best tags for the prototype.

\subsection{Approach}

\subsubsection{Accidents Due to Traffic Signal Jumping}

RFID readers would be installed under the roads and RFID tags on the cars. In case of traffic signal jumping, the offender's fine would be added to the user's portal. Since people fear of being penalized monetarily, they would avoid the traffic signal jumping.

\subsubsection{Accidents Due to Over speeding}

Over speeding is one of the major causes of road accidents. The prototype being developed is also capable of detecting over-speeding... In order to minimize the potential accident situation, an indicator would be utilized to inform the driver about slowing down.

\subsubsection{Emergency Vehicles Stuck In Traffic Jams}

According to a research $11 \%$ patients die in ambulance due to delays in traffic jams. This scenario is quite prominent in India. In order to address the issue, the prototype developed would detect the Ambulance's RFID tag, confirm it via database. Post that all traffic signals for that particular route would be turned green to enable the ambulance to reach hospital in time.

\subsubsection{Missuses of Emergency Lanes}

In certain countries, emergency lanes have been built to enable emergency vehicles to avoid issues of traffic jams. However, certain people misuse the emergency lane. In order to avoid such situations, prototype designed would result in fine issuance to offenders.

\subsubsection{Tracking A Lost Vehicle}

What happens to the car which was stolen and doesn't have latest tracking system? Well it can't be traced. However, the porotype being developed would address this too. The policeman has to register the vehicle number on the website/app. The prototype would initiate the vehicle search registered as lost. The moment the lost vehicle crosses a traffic signal fitted with RFID reader, administrator would know the lost vehicle's location. This would further enable the policemen to take further action.

\subsubsection{Driving Without Seat-Belt and Helmet}

Riding without Helmets and Driving without Seatbelts is a risky preposition. In order to make helmet mandatory for riders, a technology is being developed. It wouldn't allow the engine to turn 
on till the rider wears a helmet. For the same a pulse sensor, a wireless transmitter and receiver is utilized. The moment pulse sensor senses a constant heartbeat; it will transmit data through transmitter enabling the engine to turn on. After the vehicle receives the data from the transmitter, relay which would be applied on the shock plug which will turn on and the shock plug will be able to turn on the engine of the two-wheeler.

For cars, a relay would be utilized which would cut off the current of the shock plug. As soon as the seat belt is applied the car would be able to start as the shock plug would be able to send electric current so that vehicle would start.

\subsubsection{Drink and Drive}

For Drink and driving cases, an alcohol sensor would be installed in the car. When the alcohol level in the car is higher than an acceptable level, the car engine would automatically stop. The relay applied on the shock plug would be turned off and now the engine can't be turned on until the alcohol level returns to acceptable level or lower.

\subsection{Paying and Viewing Fines}

The moment an offender is issued a fine he/she would be receiving an email notification, an Android Application notification and a SMS. Post that the offender needs to login into their account in order to view their fines. The offender could pay via Debit Cards or Credit Cards.

\subsection{Android Application Working}

Android Application named "E-Challan" means an Electronic fine in Indian Language is a highly developed application. It consists of the following features:

i. User's Login having details of user's login details

ii. Administration Login Page containing some dynamic features

iii. Police-Officer Login who can add fine for a user if he caught him for any other situation

iv. Adding Fine Page

v. 'CONTACT US' provides a way for communication between the user and administrator for any complaints and queries 
Figure 3: A screenshot of my Android Application

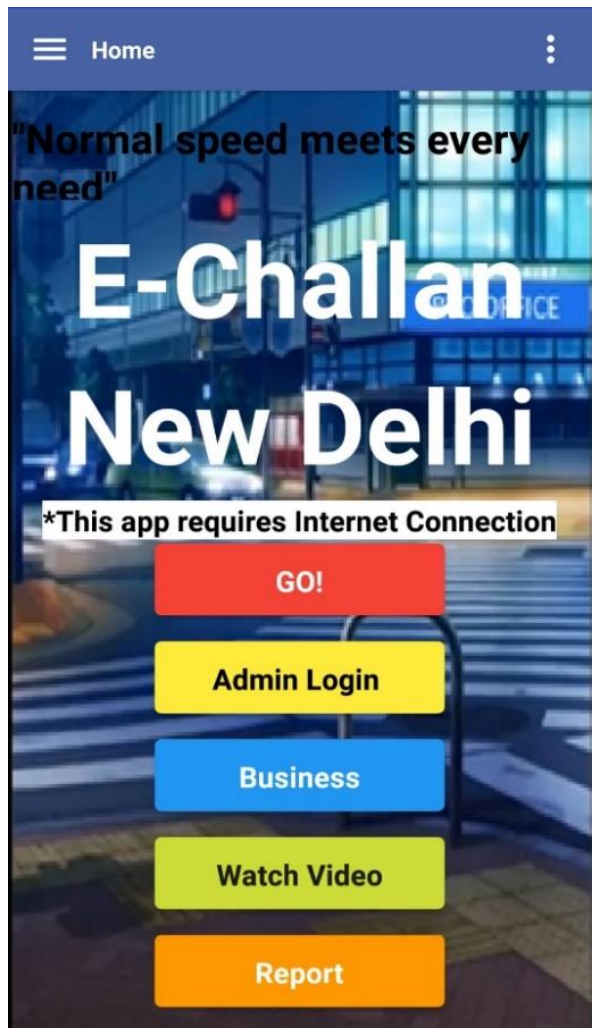

\section{Conclusion}

Utilizing the prototype being developed is anticipated to bring down the accidents by 70 $80 \%$. The preliminary results are quite encouraging. This prototype would enable the constitutional framework to be quick and highly effective. In addition, it would generate revenue for the government, reduce the corruption, reduce the damage to public property, reduce idle time etc.

Table 2: Comparison of Currently installed Road Fine issuing system in India vs My System

\begin{tabular}{|c|c|c|}
\hline & $\begin{array}{c}\text { CURRENTLY SYSTEM } \\
\text { INSTALLED IN INDIA }\end{array}$ & \\
\hline $\begin{array}{c}\text { IMAGE } \\
\text { CAPTURE }\end{array}$ & & \\
\hline $\begin{array}{c}\text { SENDING } \\
\text { FINES }\end{array}$ & & \\
\hline $\begin{array}{c}\text { VEHICLE } \\
\text { IDENTIFICATION }\end{array}$ & \\
\hline $\begin{array}{c}\text { FAKE LICENCE PLATE } \\
\text { RECOGNITION }\end{array}$ & \\
\hline
\end{tabular}




\begin{tabular}{|c|c|c|}
\hline MAKES WAY FOR & \\
EMERGENCY VEHICLE & & \\
\hline SYSTEM & & \\
AUTOMATICALLY & \\
SEND FINE FOR & & \\
OVERSPEEDING & & \\
EASY FOR USER TO & & \\
PAY FINE & HAD TO GO TO RTO & \\
& OFFICE TO PAY FINE & \\
\hline
\end{tabular}

Source: NONE

\section{How It Answers the Original Question: -}

The project has very well addressed the question that "why can road accidents not be prevented". The prototype being developed is a great success and has exceeded the expectations. The prototype usage has proven that accidents can be prevented to a large extent. In addition, utilization of computers would minimize the human interference resulting in higher efficiency, quick turnaround time, transparency, reduced corruption. It paves the paves way for a better future, and safer roads.

Figure 3: No. of Successful Readings of vehicles between currently installed system vs my system

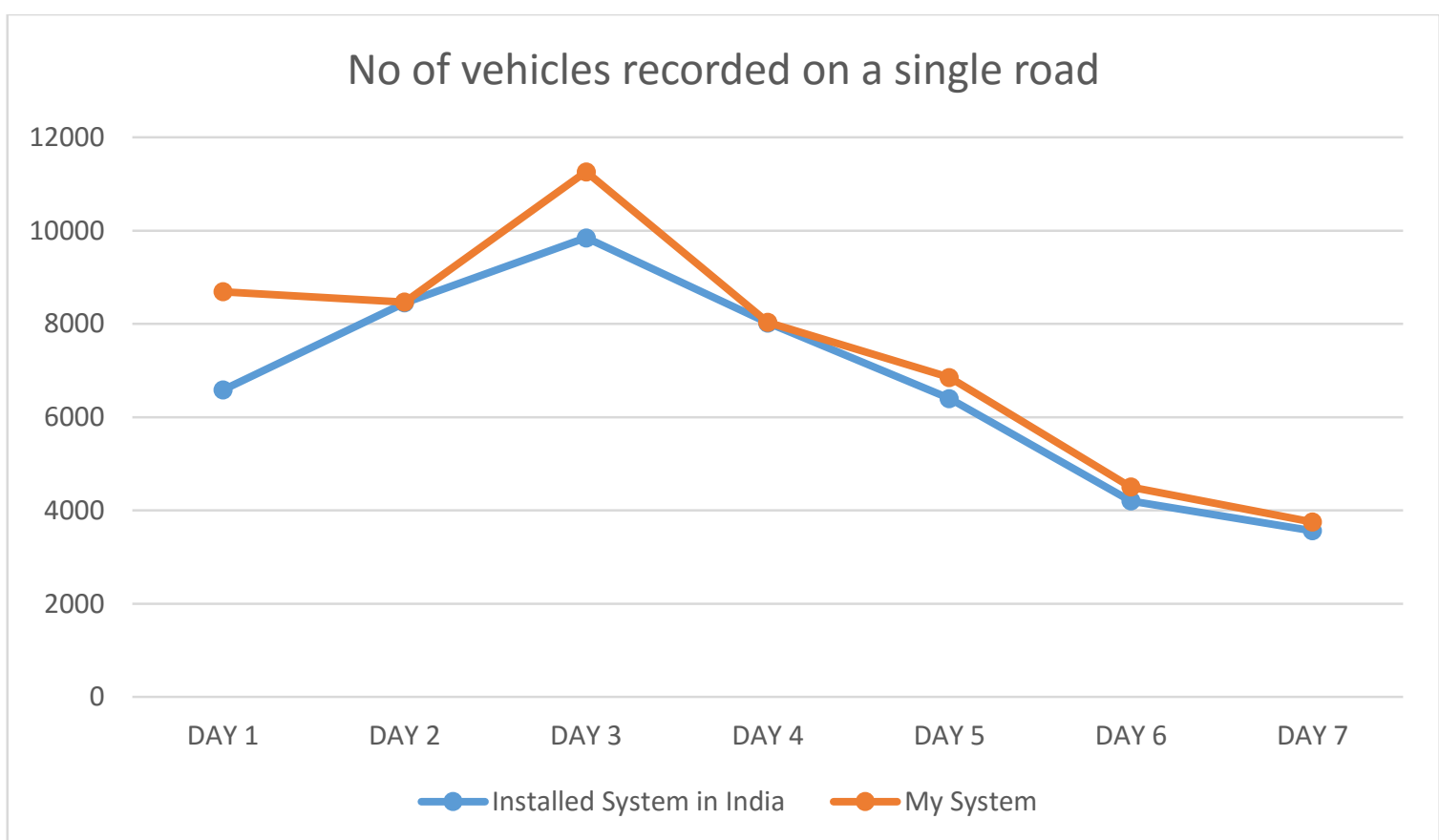


Figure 4: No. of deaths per month due to Accident: before applying my System vs after applying my System

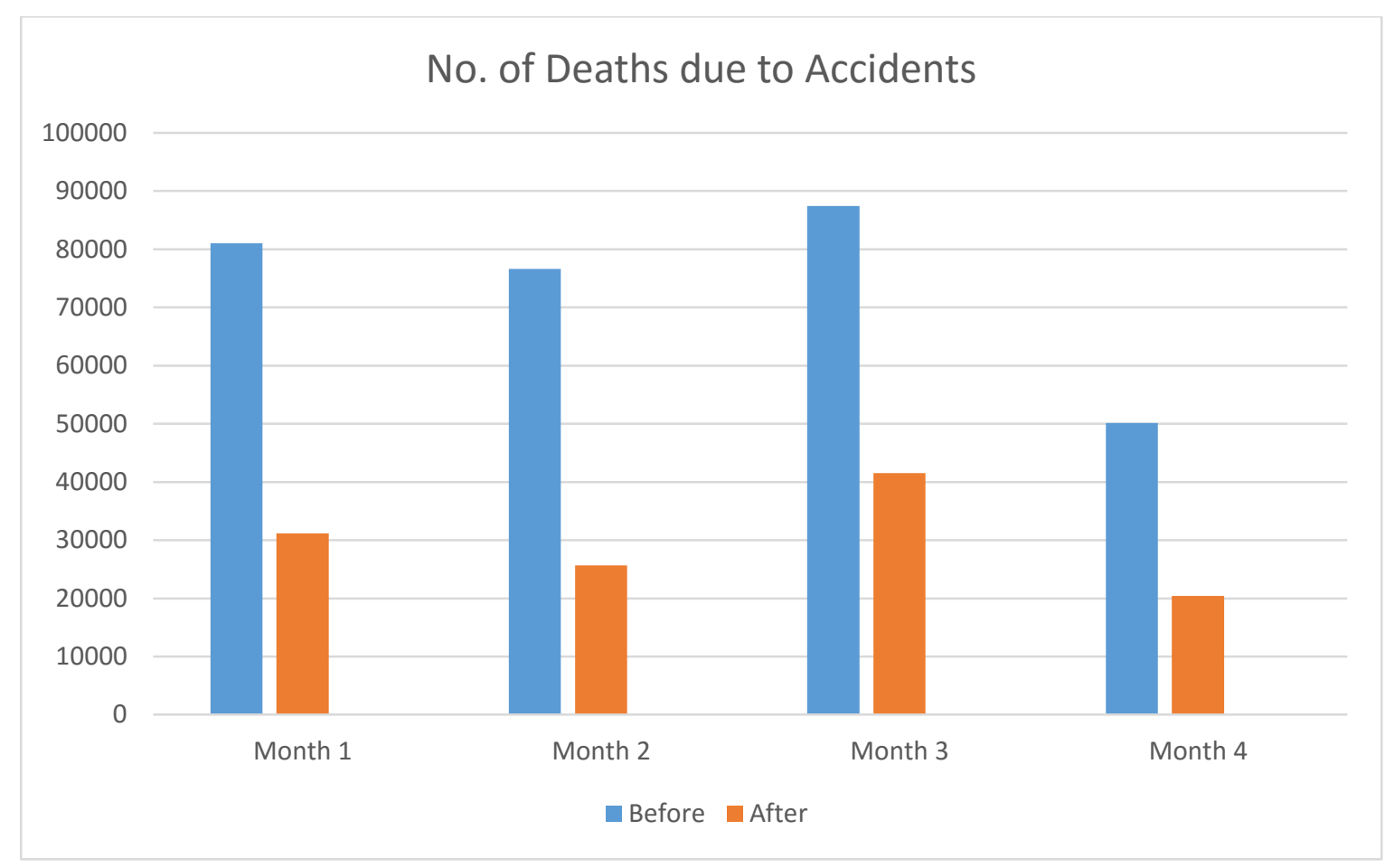

*Rough Estimate

\section{References}

Following is the list of all the resources to make this project possible.

[1] WORLD HEALTH ORGANISATION - Top 10 Causes of Death available at: https://www.who.int/news-room/fact-sheets/detail/the-top-10-causes-of-death [2] OUR WORLD IN DATA - Statistics for Road accidents available at: https://ourworldindata.org/causes-of-death

[3] SIMPLY RFID - Statistics of RFID tags and Readers link at: https://simplyrfid.com [4] INDIAN ENVIRONOMENTAL DATA - http://www.indiaenvironmentportal.org.in/ 
Figure 5: QR code for Downloading Mobile Application Visiting Website

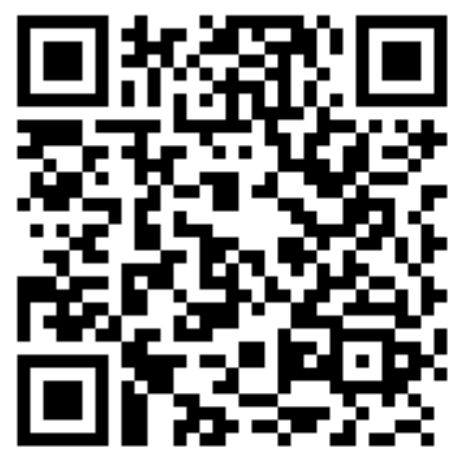

Figure 6: QR code for

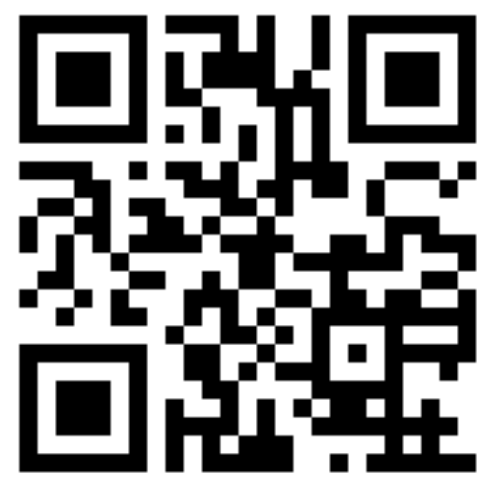

